\title{
Epidermal Growth Factor in Healing Diabetic Foot Ulcers: From Gene Expression to Tissue Healing and Systemic Biomarker Circulation
}

\author{
Jorge Berlanga-Acosta DVM MS PhD, Hanlet Camacho-Rodríguez MS, Yssel Mendoza-Marí PhD, Viviana Falcón-Cama MD PhD, \\ Ariana García-Ojalvo PhD, Luis Herrera-Martínez MD PhD, Gerardo Guillén-Nieto MS PhD
}

\begin{abstract}
Lower-extremity diabetic ulcers are responsible for $80 \%$ of annual worldwide nontraumatic amputations. Epidermal growth factor (EGF) reduction is one of the molecular pillars of diabetic ulcer chronicity, thus EGF administration may be considered a type of replacement therapy. Topical EGF administration to improve and speed wound healing began in 1989 on burn patients as part of an acute-healing therapy. Further clinical studies based on topically administering EGF to different chronic wounds resulted in disappointing outcomes. An analysis of the literature on unsuccessful clinical trials identified a lack of knowledge concerning: (I) molecular and cellular foundations of wound chronicity and (II) the pharmacodynamic requisites governing EGF interaction with its receptor to promote cell response. Yet, EGF intra- and perilesional infiltration were shown to circumvent the pharmacodynamic limitations of topical application. Since the first studies, the following decades of basic and clinical research on EGF therapy for problem wounds have shed light on potential uses of growth factors in regenerative medicine. EGF's molecular
\end{abstract}

\section{INTRODUCTION}

Diabetic foot ulcers (DFU) are one of the most feared complications of diabetes. It is a common cause of nontraumatic amputation, resulting in significant disability, morbidity and mortality.[1] An ulcer is the distal expression of an impaired healing process with a high rate of recurrence, so that patients who have temporarily achieved wound closure are considered to be remission rather than healed.[1]

The glycemic imbalance and other diabetes-related factors contribute to sculpt an epigenetic blueprint that results in a sort of "stagnant transcriptome"[2,3] in which precocious senescence, proliferative refractoriness, and apoptosis appear to be critical

\begin{abstract}
IMPORTANCE
This article describes the molecular mechanisms of epidermal growth factor (EGF) pharmacological activity, and links gene response to organ system homeostasis. The depicted cascade of events may underlie the clinical efficacy of locally-infiltrated EGF in restoring the healing response of high-grade diabetic foot ulcers. To our knowledge, this is the first comprehensive description of how EGF reverts the chronic wound phenotype in a meaningful clinical scenario when properly delivered to responsive cells.
\end{abstract}

and biochemical effects at both local and systemic levels are diverse: (1) downregulation of genes encoding inflammation mediators and increased expression of genes involved in cell proliferation, angiogenesis and matrix secretion; (2) EGF intervention positively impacts both mesenchymal and epithelial cells, reducing inflammation and stimulating the recruitment of precursor circulating cells that promote the formation of new blood vessels; (3) at the subcellular level, upregulation of the EGF receptor with subsequent intracellular trafficking, including mitochondrial allocation along with restored morphology of multiple organelles; and (4) local EGF infiltration resulting in a systemic, organismal repercussion, thus contributing to attenuation of circulating inflammatory and catabolic reactants, restored reduction-oxidation balance, and decreased toxic glycation products and soluble apoptogenic effectors. It is likely that EGF treatment may rearrange critical epigenetic drivers of diabetic metabolic memory.

KEYWORDS Epidermal Growth Factor, diabetes, diabetes complications, wound healing, diabetic foot, amputation, ulcer, Cuba

drivers resulting in wound chronicity.[4] These biological deterrents have been related to a substantial reduction in availability and activity of several growth factors, as major players of internal and peripheral tissue repair.[5,6]

The diabetic wound microenvironment is hostile to the chemical integrity and bioavailability of local growth factors (GF) and ultimately, to their role in the healing process. Examples of these growth factors include EGF, Platelet-Derived Growth Factor (PDGF), Transforming Growth Factor beta-1 (TGF- $\beta$ 1), and Insulin-Like Growth Factor I (IGF-1).[7-9] The expression and transduction signaling of EGF and PDGF receptors are also impaired within the diabetic environment.[9] Accordingly, as described for the molecular mechanisms operating in peripheral insulin resistance, it may be that diabetic wound cells exhibit reduced tyrosine kinase activity, accounting for loss of function of the growth factor receptor, which predisposes cells to proliferative arrest and senescence.[10]

In 1962, Stanley Cohen announced EGF isolation and purification from salivary glands. EGF was shown to induce precocious development and maturation of epidermal tissue and its appendages when injected into newborn mice. In other words, EGF induced maturational reprogramming of chronologically imprinted events. This is the most studied growth factor in wound healing, given its ability to promote epithelial and mesenchymal cell proliferation.[11] Yet, circulating EGF levels are reduced by 
diabetes,[12] contributing to development of local and systemic complications.[13,14] Consequently, EGF and other deficient growth factors are exogenously administered as a replacement therapy in diabetes, as an attempt to restore physiological healing processes.[13,14]

Topical administration of recombinant human EGF dates back more than 30 years. Initially, it was thought to be an encouraging alternative to combat the torpid healing of problem wounds. [15] However, the history of GF pharmacology in wound healing suggests that EGF's clinical introduction was rather precocious, at a time when basic knowledge on the biology of chronic wounds remained elusive. Initial clinical trials proved disappointing, as topical EGF administration failed to enhance a healing response in chronic wounds,[16] even in acute, experimentally induced wounds in healthy volunteers.[17]

In line with the notion that EGF reverses the proliferative arrest that characterizes chronic wounds, $[18,19]$ we introduced EGF administration through local infiltration to treat high grade DFU (for review see [18]). It was our hypothesis that intralesional infiltration could circumvent the limitations confronted during years of topical EGF administration.

The infiltration protocol calls for an EGF liquid formulation to be injected locally in the wound, at a depth of $6 \mathrm{~mm}$ to $10 \mathrm{~mm}, 3$ times a week for 5 to 8 weeks, targeting the wound bottom and dermo-epidermal junction. The decision to use this delivery mode resulted from insights accumulated from animal models and ex vivo and in vitro experiments, further enriched by valuable conclusions obtained by others.[18,20-22] These studies were possible given the availability of high-purity recombinant human EGF manufactured at the Genetic Engineering and Biotechnology Center, Havana, Cuba.[23]

A nationwide clinical development program started in Cuba in 2001,[24] which ultimately included pharmacovigilance studies that confirmed the safety and efficacy of EGF delivery by intralesional infiltration. Almost 20 years of clinical practice have shown a $75 \%$ probability of complete granulation response, $61 \%$ of complete healing; $16 \%$ absolute and $71 \%$ relative reduction of amputation risk. Furthermore, recurrences were reported as an exceptional event upon a 12-month followup period.[25,26]

Despite years of international research, GF prescription for healing problem wounds remains controversial.[27] Although GF therapy is not yet included in International Working Group on the Diabetic Foot (IWGDF) recommendations, (www.iwgdfguidelines.org), EGF intralesional infiltration has nevertheless been internationally validated and recommended as adjuvant therapy for high-grade DFU, considering its benefits in resuming a normal healing process with reduction of amputation rates.[28-32]

This article summarizes the major molecular, cellular and biochemical findings supporting the clinical efficacy of EGF intralesional infiltration for DFU in the commercially available pharmaceutical formulation Heberprot-P. The drug is included in the Cuban national medication registry since June 2008 and has offered the only pharmacological alternative for the treatment of high-grade, complex diabetic ulcers.
EGF INFILTRATIVE INTERVENTION: IMPACT ON GENE EXPRESSION, TISSUE REPAIR AND CIRCULATING BIOMARKERS

Gene transcriptional response in granulation cells Although not found on hematopoietic cells, the EGF receptor is widely expressed in mammals and has been implicated in the expression of a myriad of genes during various stages of embryonic development of both epithelial and mesenchymal tissues. [33-37] Accordingly, EGF administration modifies the course of the cutaneous healing process by promoting migration and proliferation of both epithelial and mesenchymal skin cells where its receptor expression is enhanced.[15,38]

Camacho and colleagues[39] described changes in the expression of several genes encoding proteins involved in wound healing. The investigation was part of a clinical trial (IG/FCEI/ PD/0911 in the Cuban Public Registry of Clinical Trials, http:// registroclinico.sld.cu/en/trials/RPCEC00000117-En) and included paired granulation tissue biopsies from 29 patients meeting the following criteria: Wagner grade 3-4 lesions, clinical responders with complete re-epithelialization at the end of treatment, and high-quality RNA samples for differential expression studies. Of the 29 patients, 10 were randomly chosen as the minimum sample size able to detect a 1.5-fold RNA expression difference relative to the basal constitutive value (paired control) just before treatment (biopsy identified as T0). EGF (75 $\mu \mathrm{g}$ dose) was infiltrated intralesionally 3 times/week. A second biopsy (T1) was collected at the end of treatment week 2. Paired comparisons between T1 and T0 biopsies revealed a significant increase in cell proliferation modulators Cyclin-Dependent Kinase 4 (CDK4), P21 and TP53, in collagen synthesis and Extracellular Matrix remodeling gene products (Collagen type I, alpha 1 chain, Matrix Metalloproteinase 2 and TIMP2), and a concomitant reduction of some inflammation markers, including NFKB, Tumor-Necrosis Factor-alpha (TNF- $\alpha$ ) and interleukin 1 alpha (IL-1 $\alpha$ ). Local cell proliferation, synthesis and secretion of wound matrix proteins, and downregulation of inflammation mediators such as TNF- $\alpha$, are critical events for physiological healing.[10]

The authors concluded that the observed increase in P21 and TP53 is a cellular feedback mechanism limiting the intensity and duration of the EGF-induced proliferative signal. A molecular action mechanism was postulated from these findings (Figure 1).[39] Irrespective of the differences between samples collected from diabetic ulcers and neonatal keratinocytes cultured from healthy donors, the data from Blumenberg[40] on EGF effects on transcriptomes validate the induction of keratinocyte proliferation and motility associated with feedback mechanisms controlling EGF effects. In concurrence with Blumenberg's study, our data indicate that EGF effects are modular and multifaceted rather than all-or-nothing events. This is the first clinical study addressing the transcriptomic effect of EGF in a model of human diabetic ischemic ulcers.

EGF intervention to ameliorate the histological aspect of neuropathic and ischemic lesions Ischemic diabetic lesions are characterized by a hyaline aspect matrix and paucity of functional neovessels, as well as angiogenesis defects (Figure 2A). In sharp contrast, neuropathic lesions appear to granulate earlier, exhibiting a poor collagen matrix deposition, an image similar to a spider web of thin collagen fibers, which react weakly to Mallory 
Figure 1: Changes in gene expression upon EGF infiltrations

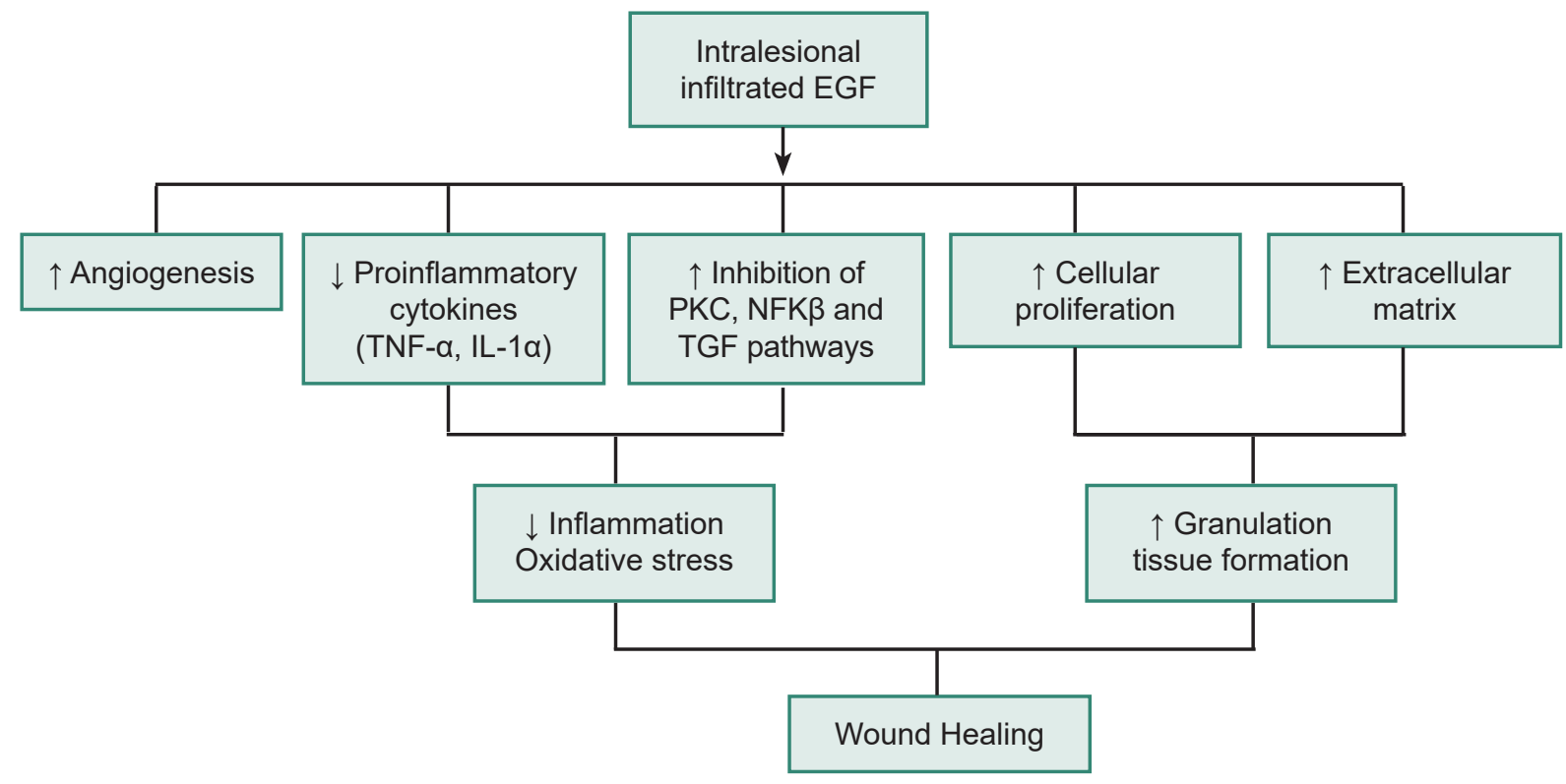

Patients who responded to EGF intralesional infiltrations exhibited gene expression changes that assisted in resuming and sustaining wound healing, and a reversion of the chronic phenotype. The clinical response was mediated by an elevation of angiogenesis, cell proliferation, and matrix fibrogenic ingredients coding genes and a reduction in inflammation related genes, stimulating the tissue repair process. (Reproduced from [39] under CC4 license).

staining. Additionally, reduced density of extracellular matrixproducing cells has also been noted (Figure 2B). As opposed to ischemic ulcers, small capillaries are observed, often surrounded by peripheral fibrin cuffs, suggesting hyperpermeability.[41] Following 9 to 12 EGF infiltration sessions (third/fourth week of treatment), granulation tissue of both ischemic and neuropathic origins exhibited substantial clinical amendment, with a consistent increase of functional small-caliber vessels across the ischemic tissue (Figure 2C). The granulation tissue matrix of neuropathic lesions becomes densely indurated by thicker and compact collagen bundles accompanied by increased productive cellularity (Figure 2D). In both scenarios, the inflammatory infiltrate appears substantially reduced.[42] Therefore, EGF positively impacts the local microenvironment of both pathogenic classifications of DFU.

It is of relevant therapeutic significance that EGF infiltration changes the biology of ischemic ulcers. Given its angiogenic effect, in addition to creating de novo vessels,[43] EGF acts as a cytoprotective agent, enhancing cell and tissue survival in otherwise lethal episodes like ischemia/reperfusion and hypoxia. [21,44-47] This drives a hypothesis that agonistic stimulation of EGF receptor (EGFR) triggers survival signals that may depend on translational modifications, with tyrosine phosphorylation being the most common.[48,49]

Zhang and colleagues recently conducted a thorough characterization of molecular mechanisms underlying EGF's effect on diabetic wounds.[50] The authors implemented a full-thickness wound model in type-2 diabetic rabbits. The EGF-induced effect after one month of daily dermal delivery is reminiscent of the microscopic outcomes identified in patient biopsies: (1) increased granulation tissue with elevation of clustered fibroblasts, (2) abundant extracellular matrix, indurated by dense and ordered collagen bundles, (3) increased active vessels and (4) attenuation of the inflammatory infiltrate. Interestingly, and aside from the histological findings, EGF treatment induced the transcription of its own gene with an increased EGF-mRNA accumulation.[50]

The EGF-induced modifications in problem wounds with different pathogenic ingredients suggest that locally-infiltrated EGF stimulates both mesenchymal and ectodermal cell responses, expressed by proliferation, migration, secretion, angiogenesis and survival. Accordingly, EGF infiltration is a DFU-specific therapy that may synchronize local cellular behaviors, thus reversing the chronicity phenotype.[51]

EGFR intracellular trafficking: EGF induces its own receptor expression in granulation tissue fibroblasts By means of immunoelectron microscopy of ulcer fibroblasts, Falcón-Cama[52] characterized EGFR time-point kinetic intracellular trafficking. EGF locally infiltrated into Wagner's 3 and 4 neuropathic ulcers translated into:

(a) Significant increase of EGFR membrane expression 15 minutes after EGF infiltration as compared to T0;

(b) Immediate EGFR endocytosis;

(c) Translocation and biodistribution to different cytoplasmic organelles from 15 minutes to 24 hours after infiltration;

d) Nuclear translocation of EGFR and its binding to DNA, which appeared to last from minute 45 to 24 hours after treatment;

(e) Concomitant activation of proliferating cell nuclear antigen (PCNA) gene transcription which appeared to last for about 24 hours after treatment;

(f) Substantial EGFR accumulation in mitochondria, which peaked between hours 6 and 24 after infiltration; and

(g) EGFR accumulation bound to extracellular matrix-secreted collagen fibers, along with abundant appearance of exosomal extracellular vesicles. 
Figure 2: Wound matrix transformation by locally infiltrated EGF
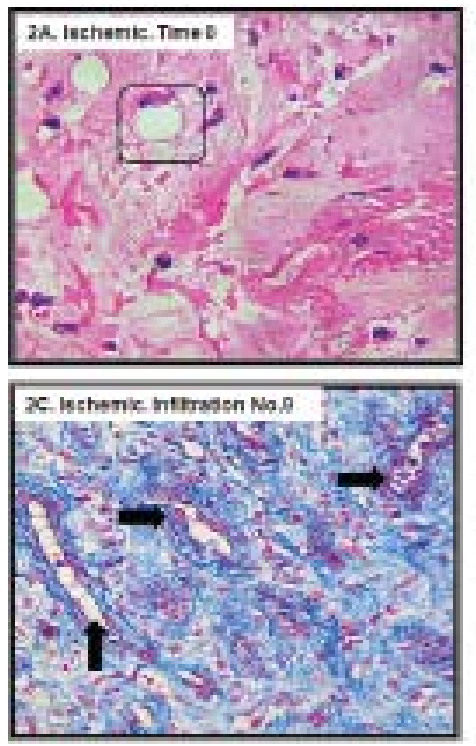

Source: Jorge Berlanga-Acosta. Archives of the laboratory of experimental pathology. Center for Genetic Engineering and Biotechnology. Havana. Cuba.

Histological images of granulation tissue biopsies collected prior to the initial EGF infiltrative intervention and after the 9th intervention. Images are representative of the two major etiopathogenic forms of diabetic lower extremity disease: ischemic and neuropathic. 2A: Representative of a clean, ischemic diabetic granulation tissue bed before the first local EGF infiltration. Granulation tissue exhibits a "hardened" hyaline matrix with a general scarceness of functional neovessels. Nonfunctional capillaries are seen since early stages (enclosed). 2B: Representative of an early granulation tissue matrix, collected from a neuropathic lesion exhibiting poor extracellular matrix accumulation, scarce collagen deposition and a limited productive cellularity before EGF treatment. These are all histological hallmarks of protracted, poor healing of neuropathic wounds. 2C: Image showing the transformation of the wound matrix composition, with substantial angiogenic response induced by the local EGF infiltration with patent large vessels (arrows) across the microscopic field of an ischemic lesion. 2D: Accumulation and organization of a substantial amount of new extracellular matrix material is conspicuous. There are functional vessels across the wound area after EGF infiltration. Biopsies from 2C and 2D were collected upon the 9th EGF infiltration session. Figure 2 conclusively denotes that EGF infiltration may positively impact on the healing biology of both ischemic and neuropathic wounds. All samples are $5 \mu \mathrm{m}$ sections and Mallory stained $X 40$. Original unpublished images.

Most importantly, ultrastructural characterization of the fibroblastlike cells 24 hours after EGF exposure revealed significant changes, suggesting organelle repair as compared to T0.[52] Figures 3A and $3 B$ reflect how EGF resulted in effective treatment for control of the rough endoplasmic reticulum (RER) dilation. At 24 hours after EGF intervention, RER tubules and cisternae appeared far less dilated as compared to T0. Similarly, mitochondria were also a target of EGF effect (Figures $3 \mathrm{C}$ and $3 \mathrm{D}$ ). The latter show a far less dilated organelle in which matrix cristae are observed. The presence of two adjacent organelles may suggest an active process of mitochondrial fission.

Although prior evidence had indicated that EGF can induce the expression of its own receptor,[53] current research provides the first evidence concerning EGFR transcriptional induction, internalization and intracellular trafficking kinetics in response to a therapeutic intervention with an EGFR ligand in a clinical setting.[52] This intense EGF-induced cellular response is consistent with its broad biological activity. In vitro models have documented that EGFR activation upon EGF binding induces the phosphorylation of 2244 proteins at 6600 catalytic sites,[54] the expression of 3172 genes and 596 proteins which are significantly altered in epithelial cells.[55]

In vitro evidence shows that full length EGFR translocates to the cell nucleus after ligand binding, $[29,56]$ where several functions are performed.[57] First, EGFR operates as a co-transcription factor regulating the expression of cyclin D1, a proximal driver of cell proliferation.[58,59] EGFR interacts with DNA-dependent protein kinase, leading to the repair of DNA double-strand breaks.[60] Furthermore, nuclear EGFR phosphorylates chromatin-bound PCNA, thus increasing its stability and eventually enhancing cell proliferation.[61] Intracellular PCNA is related to antiapoptotic activity, which may act as one of the multiple mechanisms mediating EGF pro-survival effects in a variety of cell populations.[62] Supporting this notion is the identification of the mitochondrion as another EGFR translocation compartment. Mitochondria are the hub of cellular metabolism, survival and death; they modulate not only apoptosis, but also autophagy. EGFR translocates to mitochondria where it phosphorylates cytochrome $\mathrm{C}$ oxidase subunit II , resulting in decreased cyclooxygenase activity, thus eventually preventing apoptosis.[63] EGF is also involved in mitochondrial fission,[64] fusion[65] and ultimately, in control of cellular response to stress, where it plays a pro-survival role.[37]

EGF infiltration sequentially activates EGFR in dormant ulcers, fibroblasts, and in its intracellular trafficking, promotes fibroblast proliferation, migration and survival. $[59,66,67]$ The fact that EGF may reduce RER dilation, ameliorate mitochondrial damages, and stimulate proliferation of fibroblasts in DFU drives speculation that EGFR stimulation may mitigate senescence-related traits. Although this hypothesis has yet to be experimentally verified, evidence from our group and others support this possibility.[68,69]

Locally infiltrated EGF reduces diabetic dyshomeostasis Oxidative stress not only promotes the onset of diabetes but also exacerbates the disease and its complications. Brownlee[70] proposed oxidative stress as a major operator in the pathophysiology of diabetes and its complications.[71] Hyperglycemia has been invoked to promote oxidative stress through free radical generation and ensuing deterioration of antioxidant defense systems.[71] Chronic wounds are considered a prooxidative organ superimposed upon a preexisting dysmetabolic host (the diabetic patient).[18,72] In a small cohort of diabetic neuropathic ulcers, García-Ojalvo and colleagues addressed whether an improved systemic reduction-oxidation (redox) balance is associated with healing response in patients infiltrated with EGF.[72] The rationale for the above study was supported by previous experiments demonstrating that EGF reduced levels of oxidative stress biomarkers, ultimately attenuating cytotoxic damage.[73-76] After 3 to 4 weeks of EGF treatment (9 to 12 infiltration sessions), 4 circulating biomarkers (erythrocyte sedimentation rate, IL-6, soluble FAS and pentosidine) were significantly reduced, while antioxidant parameters increased. 
Figure 3: Impact of EGF treatment on ulcer-fibroblasts organelles repair

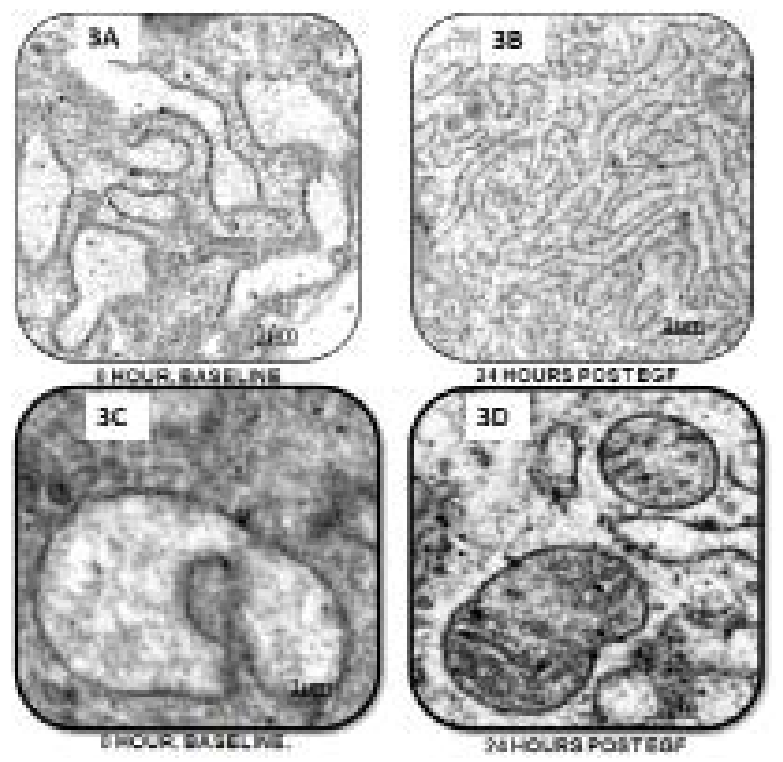

3A. Electron microscopy image of the rough endoplasmic reticulum (RER) at time 0 . Sample collected before EGF infiltration. The dilation and distortion of the RER cisternae is evident.

3B. Effect of EGF intervention after reverting cisternae dilation and ameliorating the preexisting distortion after 24 hours of treatment.

3C. Electron microscopy image of a ballooned mitochondria showing its notable dilation and disappearance of internal cristae before the first EGF intervention. A fine granulation is dispersed within the mitochondrial matrix.

3D. Twenty four hours after the EGF treatment, it is noticeable the substantial transformation of the mitochondria. Mitochondria are far less ballooned with matrix content and exhibiting some cristae.

Source: Falcón-Cama V, et al.[52]

Notably, at least $50 \%$ of patients showed a favorable response for each evaluated marker. EGF's molecular effect was simultaneously associated with a positive clinical response in terms of granulation, contraction and re-epithelialization. This was the first clinical validation of in vitro and animal data indicating that EGF's cytoprotective effect is at least partially mediated by correcting the redox balance.[18,73,76-78]

A more recent study by García-Ojalvo and colleagues[79] confirmed previous observations concerning the systemic impact of locally-infiltrated EGF on reestablishment of a physiological redox balance. Moreover, the new data indicates that EGF's effect extends to reduction of diabetic endovascular pro-inflammatory markers. Within three weeks of treatment, patients showed significant reduction of: erythrocyte sedimentation rate, IL-6 circulating levels, soluble FAS and the glycoxidation product pentosidine, as well as a significant reduction of oxidative and nitrosilative stress markers (Table 1).

The fact that EGF infiltration reduced circulating levels of IL-6 is highly significant in diabetes. IL- 6 is perhaps the bestreputed bona fide cytokine, pathogenically involved in the primary event of insulin resistance, in the morbidity caused by multiorgan complications, and in the onset of a poor healing
Table 1. Systemic effects of locally infiltrated EGF in patients with diabetic foot ulcers

$\begin{array}{lll}\text { System } & \text { Systemic effect } \\ \text { Redox balance } & \downarrow \text { Total oxidative capacity } \\ & \downarrow \text { MDA } \\ & \downarrow \text { AOPP } \\ & \downarrow \text { Total organoperoxides } \\ & \downarrow \text { Nitrite/Nitrate ratio } \\ & \uparrow \text { Total antioxidant capacity } \\ & \uparrow \text { SH groups } \\ & \downarrow \text { Erythrosedimentation } \\ \text { Anti-inflamatory mechanism } & \downarrow \text { C Reactive Protein } \\ & \downarrow \text { IL-6 } \\ & \downarrow \text { MIP1-a } \\ & \downarrow \text { sFAS } \\ & \downarrow \text { Pentosidine } \\ \text { AGE pathway } & \uparrow \text { sRAGE } \\ \text { Extracellular matrix } & \downarrow \text { MMP-9 } \\ & \downarrow \text { TIMP-1 }\end{array}$

Diabetic patients with lower limb wounds were treated with intralesional infiltrations of EGF $(75 \mu \mathrm{g})$, three times per week during 3-4 weeks $[72,79]$. Systemic antioxidant effects: decrease of circulating levels of total oxidative capacity, malondialdehyde (MDA), advanced oxidation protein products (AOPP), total organoperoxides, and nitrite/nitrate ratio; increase of total antioxidant capacity and sulfhydryl (SH) groups. Anti-inflammatory effects: reduction in erythrosedimentation, $\mathrm{C}$ reactive protein, interleukin-6 (IL-6), macrophage inflammatory protein 1-alpha (MIP1-a), and soluble FAS (sFAS). Systemic attenuation of the advanced glycation end (AGE) pathway: decrease in pentosidine, increase in the soluble receptor for AGE (RAGE) circulating levels. Extracellular matrix elements modulated at the systemic level: reduction of matrix metalloprotease 9 (MMP-9) and tissue inhibitor of MMP 1 (TIMP-1).

response. In vitro studies by our group reproducibly show that DFU-derived fibroblasts exposed to lipopolysaccharides exhibit a highly significant increase of IL-6, which returned to basal levels, similar to those of untreated cells, after adding EGF (Yssel Mendoza-Marí, manuscript in preparation. April 2020). Simply said, dampening IL-6 circulating levels could contribute to restoration of metabolic homeostasis in diabetic patients.[80-82] Aside from IL-6, EGF intervention also reduced serum levels of soluble FAS and the chemokine Macrophage Inflammatory Protein (MIP1- $\alpha$ ). Although further studies are clearly needed, collectively this evidence suggests that EGF may have assisted in reduction of insulin resistance, attenuation of endovascular inflammation and reduction of apoptotic rates; thus attenuating premature diabetic organ senescence.[83] Conclusively, EGF treatment exhibits broad systemic pharmacodynamics that go beyond the reestablishment of redox balance.

\section{CONCLUSIONS}

The discovery of growth factors initiated a new era in wound healing biology and held out hope for recalcitrant wound treatment. EGF, the prototypic and founding member of the EGFR ligand family, led to use of topical administration of growth factors for wound healing. Evidence suggests its role in tissue repair was already apparent in the early 1960s in Stanley Cohen's work subjecting rabbits to corneal burns followed by treatment with homemade natural EGF eye drops.[11] Despite the initial promise and years of research, growth factors have not garnered a definitive acceptance in the 
clinical toolbox for wound management. Lessons learned over the past decades reinforce the importance of growth factor stability, which allows for sufficient residence time within the wound matrix to achieve the expected pharmacodynamic response. Cleverly engineered formulations are emerging that may yet vindicate growth factors' intrinsic biological potential. The intralesional infiltrative procedure, despite its simplicity, safeguards EGF bioactivity for prolonged periods, thus emphasizing the concept that spatio-temporal control of EGF availability is fundamental for clinical success.

This pioneer growth factor has proved to modify gene and protein expression, phosphorylate catalytic sites, modulate organelle homeostasis and, at an organismal level, reverse changes in inflammatoxic markers involved in progression of diabetic complications. The latter may represent the systemic effects of EGF, accompanied by amelioration of the wound chronicity phenotype. Again, wound-host bidirectional communication is underscored.

A research challenge is elucidation of the molecular foundations that may explain the unusual EGF trait of helping to prevent ulcer recurrence over the long term.[25,26] We hypothesize that infiltrated EGF exerts a local 'rejuvenating' effect by replacing senescent cells or by dismounting or reversing the fibroblasts' epigenetic senescence program. Thus, EGF may potentially act as a senolytic agent for diabetic wounds, promoting neodermal resilience and tolerance to physical and mechanical stress.

In conclusion, two decades of clinical and basic research on EGF therapy for problem wounds have shed light on the utility of growth factors with broad pharmacological potential in regenerative medicine; the time has come to focus on how, when and where to deliver their messages to their targets. $-1 /$ -

\section{REFERENCES}

1. Armstrong DG, Boulton AJM, Bus SA. Diabetic foot ulcers and their recurrence. $\mathrm{N}$ Engl $\mathrm{J}$ Med. 2017 Jul 15;376(24):2367-75.

2. Biswas S, Roy S, Banerjee J, Hussain SRA, Khanna S, Meenakshisundaram G, et al. Hypoxia inducible microRNA 210 attenuates keratinocyte proliferation and impairs closure in a murine model of ischemic wounds. Proc Natl Acad Sci U S A. 2010 Apr 13;107(15):6976-81.

3. Caporali A, Meloni M, Nailor A, Mitic T, Shantikumar S, Riu F, et al. p75(NTR)-dependent activation of NF-kappaB regulates microRNA-503 transcription and pericyte-endothelial crosstalk in diabetes after limb ischaemia. Nat Commun. 2015 Aug 13;6.

4. Berlanga-Acosta J, Mendoza-Marí Y, García-Ojalvo A, Acosta-Buxado JA, Fernández-Mayola M, Guillén-Nieto G. Epidermal Growth Factor (EGF) intralesional infiltrations: from the bench to the diabetic ulcers cells. Integr Mol Med. 2019 Feb 20;6(1):1-7.

5. Park JW, Hwang SR, Yoon IS. Advanced growth factor delivery systems in wound management and skin regeneration. Molecules. 2017 Aug;22(8):1259.

6. Yamakawa S, Hayashida K. Advances in surgical applications of growth factors for wound healing. Burns Trauma. 2019 Apr 5;7:10.

7. Blakytny R, Jude EB, Gibson JM, Boulton AJM, Ferguson MWJ. Lack of insulin-like growth factor 1 (IGF1) in the basal keratinocyte layer of diabetic skin and diabetic foot ulcers. J Pathol. 2000 Mar 22;190(5):589-94.

8. Jude EB, Blakytny R, Bulmer J, Boulton AJM, Ferguson M. Transforming growth factor-beta 1, 2, 3 and receptor type I and II in diabetic foot ulcers. Diabet Med. 2002 Jun;19(6):440-7.

9. Portero-Otín M, Pamplona R, Bellmunt MJ, Ruiz MC, Prat J, Salvayre R, et al. Advanced glycation end product precursors impair epidermal growth factor receptor signaling. Diabetes. 2002 May;51(5):1535-42.

10. Berlanga-Acosta J, Schultz GS, López-Mola E, Guillén-Nieto G, García-Siverio M, HerreraMartínez L. Glucose toxic effects on granulation tissue productive cells: the diabetics' impaired healing. Biomed Res Int. 2013;2013:256043.

11. Cohen S. Origins of growth factors: NGF and EGF. J Biol Chem. 2008 Dec 5;283(49):33793-7.

12. Kasayama S, Ohba Y, Oka T. Epidermal growth factor deficiency associated with diabetes mellitus. Proc Natl Acad Sci U S A. 1989 Oct;86(19):7644-8.

13. Dodds MWJ, Johnson DA, Yeh CK. Health benefits of saliva: a review. J Dent. 2005 Mar. 33(3):223-33.
14. Oxford GE, Tayari L, Barfoot MD, Peck AB Tanaka Y, Humphreys-Beher MG. Salivary EGF levels reduced in diabetic patients. J Diabetes Complications. 2000 May-Jun;14(3):140-5.

15. Schultz G, Rotatori DS, Clark W. EGF and TGFalpha in wound healing and repair. J Cell Biochem. 1991 Mar;45(4):346-52.

16. Falanga $\mathrm{V}$, Eaglstein $\mathrm{WH}$, Bucalo $\mathrm{B}$, Katz $\mathrm{MH}$, Harris B, Carson P. Topical use of human recombinant epidermal growth factor (h-EGF) in venous ulcers. J Dermatol Surg Oncol. 1992 Jul;18(7):604-6.

17. Cohen IK, Crossland MC, Garret A, Diegelmann RF. Topical application of epidermal growth factor onto partial-thickness wounds in human volunteers does not enhance reepithelialization. Plast Reconstr Surg. 1995 Aug;96(2):251-4.

18. Berlanga-Acosta J, Fernández-Montequín J, Valdés-Pérez C, Savigne-Gutiérrez W, Mendoza-Marí Y, García-Ojalvo A, et al. Diabetic foot ulcers and epidermal growth factor: revisiting the local delivery route for a successful outcome Biomed Res Int. 2017 Aug 21;2017:2923759.

19. Thomson S, McLennan SV, Twigg SM. Growth factors in diabetic complications. Expert Rev Clin Immunol. 2006 Apr;2(3):403-18.

20. Berlanga J, Fernández JI, López E, López PA, del Río A, Valenzuela C, et al. Heberprot-P: a novel product for treating advanced diabetic foot ulcer. MEDICC Rev. 2013 Jan;15(1):11-5

21. Berlanga-Acosta J, Gavilondo J, López-Saura PA, González-López T, Castro-Santana MD López-Mola E, et al. Epidermal growth factor in clinical practice - a review of its biological actions, clinical indications and safety implications. Int Wound J. 2009 Sep;6(5):331-46.

22. Cross SE, Roberts MS. Defining a model to predict the distribution of topically applied growth factors and other solutes in excisional full-thickness wounds. J Invest Dermatol. 1999 Jan;112(1):36-41.

23. Cinza AM, Quintana M, Lambardero R, Pontón R, Pérez E, Pérez LC, et al. Establecimiento de un cultivo discontinuo para la producción del factor de crecimiento epidérmico humano en levaduras. Biotecnol Apl. 1991 May-Aug;8(2):166-73. Spanish.

24. Acosta JB, Savigne W, Valdez C, Franco N, Alba JS, del Río A, et al. Epidermal growth factor intralesional infiltrations can prevent amputation in patients with advanced diabetic foot wounds. Int Wound J. 2006 Sep 19;3(3):232-9.

25. López-Saura PA, Yeras-Alos IB, ValenzuelaSilva C, González-Díaz O, del Río-Martín A, Ber-
langa-Acosta J, et al. Medical practice confirms clinical trial results of the use of intralesional human recombinant epidermal growth factor in advanced diabetic foot ulcers. Adv Pharmacoepidemiol Drug Saf. 2013 Mar 20;2(2).

26. Yera-Alos IB, Alonso-Carbonell L, ValenzuelaSilva CM, Tiero-Iglesias AD, Moreira M, LópezMola $E$, et al. Active post-marketing surveillance of the intralesional administration of human recombinant epidermal growth factor in diabetic foot ulcers. BMC Pharmacol Toxicol. 2013 Sep;14:44.

27. Bui TQ, Bui QBP, Németh $D$, Heygi $P$, Szakács $Z$, Rumbus Z, et al. Epidermal growth factor is effective in the treatment of diabetic foot ulcers: meta-analysis and systematic review. Int J Environ Res Public Health. 2019 Jul;16(14):2584.

28. Aktas S, Baktiroglu S, Demir L, Kilicoglu OI, Topalan M, Guven E, et al. Intralesional application of epidermal growth factor in limb-threatening ischemic diabetic foot ulcers. Acta Orthop Traumatol Turc. 2015 Dec;50(3):277-84.

29. Endres NF, Barros T, Cantor A, Kuriyan J. Emerging concepts in the regulation of the EGF receptor and other receptor tyrosine kinases. Trends Biochem Sci. 2014 Oct 1;39(10):43746.

30. Ertugrul BM, Buke C, Erzoy OS, Ay B, Senen Demires D, Savk O. Intralesional epidermal growth factor for diabetic foot wounds: the first cases in Turkey. Diabet Foot Ankle. 2015 Aug $11 ; 6(1): 28419$

31. Teran Soto JM, Gomez-Villa R, Aguilar Rebolledo F, Lozano Platonoff A, Fabian-Victoriano MR, Kresch-Tronick NS, et al. Efficacy of intralesional recombinant human epidermal growth factor in diabetic foot ulcers in Mexican patients: a randomized double-blinded controlled trial. Wound Repair Regen. 2014 Jul;22(4):497-503.

32. Kahraman M, Abdulhamit M, Kizkapan TB, Ozcamdalli M, Uzun E, Mutlu Met al. The long-term outcomes following the application of intralesional epidermal growth factor in patients with diabetic foot ulcers. J Foot Ankle Surg. 2019 Mar;58(2):282-7.

33. Bhaskar B, Mekala NK, Baadhe RR, Rao S. Role of signaling pathways in mesenchymal stem cell differentiation. Curr Stem Cell Res Ther. 2013 Dec 31;9(6):508-12.

34. Miettinen PJ, Berger JE, Meneses J, Phung Y, Pedersen RA, Werb Z, et al. Epithelial immaturity and multiorgan failure in mice lacking epidermal growth factor receptor. Nature. $1995 \mathrm{Jul}$ 27;376(6538):337-41. 
35. Moghal N, Sternberg PW. Multiple positive and negative regulators of signaling by the EGF-receptor. Curr Opin Cell Biol. 1999 Apr 1;11(2):190-6.

36. Normanno N, De Luca A, Bianco C, Strizzi L, Mancino M, Maiello MR, et al. Epidermal growth factor receptor (EGFR) signaling in cancer. Gene. 2006 Jan 17;366(1):2-16.

37. Tomas A, Futter CE, Eden ER. EGF receptor trafficking: consequences for signaling and cancer. Trends Cell Biol. 2014 Jan;24(1):26-34.

38. Nanney LB. Epidermal and dermal effects of epidermal growth factor during wound repair. J Invest Dermatol. 1990 May:94(5):624-9.

39. Camacho-Rodríguez $H$, Guillén-Pérez IA, Roca-Campaña J, Baldomero-Hernández JE, Tuero-Iglesias ÁD, Galván-Cabrera JA, et al. Heberprot-P's effect on gene expression in healing diabetic foot ulcers. MEDICC Rev. 2018 Jul;20(3):10-4.

40. Blumenberg M. Profiling and metaanalysis of epidermal keratinocytes responses to epidermal growth factor. BMC Genomics. 2013 Feb 8; $14: 85$.

41. Mendoza-Marí Y, Valdés-Pérez C, RodríguezCorrales E, Suárez-Alba J, García-Ojalvo A, et al. Histological and transcriptional expression differences between diabetic foot and pressure ulcers. J Diabetes Metab. 2013;4(8):296.

42. Acosta JB, del Barco DG, Vera DC Savigne W, López-Saura $P$, Guillén Nieto $G$, et al. The pro-inflammatory environment in recalcitrant diabetic foot wounds. Int Wound J. 2008 Oct;5(4):530-9.

43. van Cruijsen H, Giaccone G, Hoekman K. Epidermal growth factor receptor and angiogenesis: opportunities for combined anticancer strategies. Int J Cancer. 2005 Dec. 117(6):883-8.

44. Berlanga J, Prats P, Remirez D, González R, López-Saura P, Aguiar J, et al. Prophylactic use of epidermal growth factor reduces ischemia/reperfusion intestinal damage. Am J Pathol. 2002 Aug;161(2):373-9.

45. Liu Q, Djuricin G, Nathan C, Gattuso P, Weinstein RA, Prinz RA. The effect of epidermal growth factor on the septic complications of acute pancreatitis. J Surg Res. 1997 Apr;69(1):171-7.

46. Maeda $H$, Rajesh KD, Maeda $H$, Suzuki $R$, Sasaguri S. Epidermal growth factor and insulin inhibit cell death in pancreatic beta cells by activation of PI3-kinase/AKT signaling pathway under oxidative stress. Transplant Proc. 2004 May;36(4):1163-5

47. Yang $\mathrm{S}$, Jin $\mathrm{H}$, Zhao ZG. Epidermal growth factor treatment has protective effects on the integrity of the blood-brain barrier against cerebral ischemia injury in bEnd3 cells. Exp Ther Med. 2019 Mar;17(3):2397-402.

48. Singh B, Carpenter G, Coffey RJ. EGF receptor ligands: recent advances. F1000 Faculty Rev 2270. 2016 Sep 8;5.

49. Xie Y, Shi X, Sheng K, Hang G, Li W, Zhao Q, et al. PI3K/Akt signaling transduction pathway, erythropoiesis and glycolysis in hypoxia (Review). Mol Med Rep. 2019 Feb;19(2):783-91.

50. Zhang J, Hu W, Diao Q, Wang Z, Miao J, Chen $X$, et al. Therapeutic effect of the epidermal growth factor on diabetic foot ulcer and the underlying mechanisms. Exp Ther Med. 2019 Mar;17(3):1643-8.

51. Wickert LE, Pomerenke S, Mitchell I, Masters KS, Kreeger PK. Hierarchy of cellular decisions in collective behavior: implications for wound healing. Sci Rep. 2016 Feb 2;6:20139.

52. Falcón-Cama V, Fernández-Mayola M, Mendoza-Marí Y, Acosta-Rivero N, García-Ojalvo A, Bringas-Pérez R, et al. Epidermal growth factor based therapy promotes intracellular trafficking and accumulation of its receptor in the nucleus of fibroblasts from diabetic foot ulcers. J Diabetic Complications Med. 2016 Jan;1:111.

53. Clark AJ, Ishii S, Richert N, Merlino GT, Pastan I. Epidermal growth factor regulates the expression of its own receptor. Proc Natl Acad Sci USA. 1985 Dec;82(24):8374-8.

54. Olsen JV, Blagoev B, Gnad F, Kumar C, Mortensen P, Mann M, et al. Global, in vivo, and site-specific phosphorylation dynamics in signaling networks. Cell. 2006 Nov 3;127(3):635-48.

55. Waters KM, Liu T, Quesenberry RD, Wilse AR, Bandyopadhyay S, Kathman LE, et al. Network analysis of epidermal growth factor signaling using integrated genomic, proteomic and phosphorylation data. PLoS One. 2012 Mar 29;7(3):e34515.

56. Lee HH, Wang YN, Hung MC. Non-canonical signaling mode of the epidermal growth factor receptor family. Am J Cancer Res. 2015 Sep 15;5(10):2944-58.

57. Wang YN, Yamauchi H, Hsu JM, Hung MC Nuclear trafficking of the epidermal growth factor receptor family membrane proteins. Oncogene. 2010 Jul 15;29(28):3997-4006.

58. Lin SY, Makino K, Xia W, Matin A, Wen Y, Kawong $\mathrm{KY}$, et al. Nuclear localization of EGF receptor and its potential new role as a transcription factor. Nat Cell Biol. 2001 Aug 9;3(9):802-8.

59. Wee $P$, Wang Z. Epidermal growth factor receptor cell proliferation signaling pathways. Cancers (Basel). 2017 May;9(5):52.

60. Dittmann K, Mayer C, Rodemann HP. Inhibition of radiation-induced EGFR nuclear import by C225 (Cetuximab) suppresses DNA-PK activity. Radiother Oncol. 2005 Jul 31;76(2):157-61.

61. Bouayad D, Pederzoli-Ribeil M, Mocek J, Candalh C, Arlet JB, Hermine O, et al. Nuclearto-cytoplasmic relocalization of the proliferating cell nuclear antigen (PCNA) during differentiation involves a chromosome region maintenance 1 (CRM1)-dependent export and is a prerequisite for PCNA antiapoptotic activity in mature neutrophils. J Biol Chem. 2012 Sep 28;287(40):33812-25.

62. Tan X, Lambert PF, Ragraeger AC, Anderson RA. Stress-induced EGFR trafficking: mechanisms, functions, and therapeutic implications. Trends Cell Biol. 2016 May;26(5):352-66.

63. Demory ML, Boerner JL, Davidson R, Faust W, Miyake T, Lee I, et al. Epidermal growth factor receptor translocation to the mitochondria: regulation and effect. J Biol Chem. $2009 \mathrm{Dec}$ 25;284(52):36592-604.

64. Che TF, Lin CW, Wu YY, Cheng YJ, Han CL, Chang $\mathrm{YI}$, et al. Mitochondrial translocation of EGFR regulates mitochondria dynamics and promotes metastasis in NSCLC. Oncotarget. 2015 Nov 10;6(35):37349-66.

65. Bollu LR, Ren J, Blessing AM, Katreddy RR, Gao $\mathrm{G}, \mathrm{Xu} \mathrm{L}$, et al. Involvement of de novo synthesized palmitate and mitochondrial EGFR in EGF induced mitochondrial fusion of cancer cells. Cell Cycle. 2014 Aug 1;13(15):2415-30.

66. Roepstorff K, Grandal MV, Henriksen L, Kanudsen SLJ, Lerdrup M, et al. Differential effects of EGFR ligands on endocytic sorting of the receptor. Traffic. 2009 Aug;10(8):1115-27.

67. Singh $A B$, Harris RC. Autocrine, paracrine and juxtacrine signaling by EGFR ligands. Cell Signal. 2005 Oct;17(10):1183-93.

68. Berlanga-Acosta J, Mendoza-Marí Y, GarcíaOjalvo A, Fernández-Mayola M, Guillén-Nieto G. Epidermal growth factor therapy impact on scar tissue resilience of diabetic lower limbs ulcers An enlightening hypothesis. J Diabetes Metab. 2018 Jul 31:9(7):798

69. Alexander PB, Yuang L, Yang P, Sun T, Chen R, Xiang $\mathrm{H}$, et al. EGF promotes mammalian cell growth by suppressing cellular senescence. Cell Res. 2014 Nov 3;25(1):135-8.
70. Brownlee M. The pathobiology of diabetic complications: a unifying mechanism. Diabetes. 2005 Jun;54(6):1615-25.

71. Giacco F, Brownlee M. Oxidative stress and diabetic complications. Circ Res. 2010 Oct 29;107(9):1058-70.

72. Ojalvo AG, Marí YM, Mayola MF, Pérez CV, Gutiérrez WS, et al. Healing enhancement of diabetic wounds by locally infiltrated epiderma growth factor is associated with systemic oxidative stress reduction. Int Wound J. 2016 Mar 21;14(1):214-25.

73. Arda-Pirincci P, Bolkent S. The role of epidermal growth factor in prevention of oxidative injury and apoptosis induced by intestinal ischemia/reperfusion in rats. Acta Histochem. 2014 Jan;116(1):167-75.

74. Holbrook NJ, Ikeyama S. Age-related decline in cellular response to oxidative stress: links to growth factor signaling pathways with common defects. Biochem Pharmacol. 2002 Aug 31;64(5-6):999-1005.

75. Martindale JL, Holbrook NJ. Cellular response to oxidative stress: signaling for suicide and survival. J Cell Physiol. 2002 Jun 30;192(1):1-15.

76. Tang X, Liu B, Wang X, Yu Q, Fang R. Epidermal growth factor, through alleviating oxidative stress, protect IPEC-J2 cells from lipopolysaccharides-induced apoptosis. Int J Mol Sci. 2018 Mar;19(3):848.

77. Ma J, Jin G. Epidermal growth factor protects against myocardial ischaemia reperfusion injury through activating Nrf2 signalling pathway. Free Radic Res. 2019 Mar 6;53(3):313-23.

78. Ozturk AM, Sozbilen MC, Sevgili E, Dagci T, Özyalcin $\mathrm{H}$, et al. Epidermal growth factor regulates apoptosis and oxidative stress in a rat model of spinal cord injury. Injury. 2018 Jun;49(6):1038-45.

79. García-Ojalvo A, Berlanga-Acosta J, FigueroaMartínez A, Bequet M. Systemic translation of locally infiltrated epidermal growth factor in diabetic lower extremity wounds. Int Wound J. 2019 Aug;16(2):1294-303.

80. Hart J. Inflammation. 2: its role in the healing of chronic wounds. J Wound Care. 2002 Aug;11(7):245-9.

81. Kristiansen OP, Mandrup-Poulsen T. Interleukin-6 and diabetes: the good, the bad, or the indifferent? Diabetes. 2006 Jan;54 Suppl 2(2):S114-24.

82. Liaqat A, Rehman K, Rasul A, Hamid Akash MS Role of interleukin-6 in development of insulin resistance and type 2 diabetes mellitus. Crit Rev Eukaryot Gene Expr. 2017 Jan;27(3):229-36.

83. Palmer AK, Tchkonia T, LeBrasseur NK, Chin EN, Xu M, Kirkland JL. Cellular senescence in type 2 diabetes: a therapeutic opportunity. Diabetes. 2015 Jul;64(7):2289-98.

\section{THE AUTHORS}

Jorge Berlanga-Acosta (Corresponding author: jorge.berlanga@cigb.edu.cu), veterinarian with a master's degree in pathology and a doctorate in pharmaceutical sciences. Tissue repair research project leader, Genetic Engineering and Biotechnology Center (ClGB), Havana, Cuba. Member of the Cuban Academy of Sciences. https://orcid.org/0000-0001-9797-1986

Hanlet Camacho-Rodríguez, microbiologist with a master's degree in neurosciences. Associate researcher. Biomedical Research Division, CIGB, Havana, Cuba. https://orcid.org/0000 $-0001-8668-034 X$

Yssel Mendoza-Mari, biologist with a doctorate in biological sciences. Tissue Repair Research 
Laboratory, Biomedical Research Division, CIGB, Havana, Cuba. https://orcid.org/0000 -0002-2788-0701

Viviana Falcón-Cama, physician specializing in biochemistry with a doctorate in medical sciences. Head, Electron Microscopy Department, Biomedical Research Division, CIGB, Havana, Cuba. https://orcid.org/0000-0002-1825-0097

Ariana García-Ojalvo, biologist with a doctorate in biological sciences. Tissue Repair
Research Laboratory, Biomedical Research Division, CIGB, Havana, Cuba. https://orcid .org/0000-0002-9519-0139

Luis Herrera-Martínez, physician with a doctorate in biological sciences. Director, CIGB, Havana, Cuba. Advisor to BioCubaFarma's presidency.

Gerardo Guillén-Nieto, chemist with a master's degree in chemistry and doctorate in biological sciences. Professor, Medical University of Havana. Director, Biomedical Research, CIGB,
Havana, Cuba. https://orcid.org/0000-0003 $-3098-0970$

Submitted: February 17, 2020

Approved for publication: June 3, 2020

Disclosures: The authors are employed by

CIGB, Havana, Cuba, which owns the patent for the use of EGF local infiltration to reduce the risk of lower-limb amputation in diabetic populations. Jorge Berlanga-Acosta is the lead author on the patent, also authored by Gerardo Guillén-Nieto and Luis Herrera-Martínez. 